\title{
ALUMINA STRENGTH DEGRADATION IN THE ELASTIC REGIME
}

\author{
Michael D. Furnish and Lalit C. Chhabildas \\ Sandia National Laboratories, Albuquerque NM 87185
}

Measurements of Kanel et. al. [1991] have suggested that deviatoric stresses in glasses shocked to nearly the Hugoniot Elastic Limit (HEL) relax over a time span of microseconds after initial loading. "Failure" (damage) waves have been inferred on the basis of these measurements using time-resolved manganin normal and transverse stress gauges. Additional experiments on glass by other researchers, using time-resolved gauges, high-speed photography and spall strength determinations have also lead to the same conclusions. In the present study we have conducted transmitted-wave experiments on high-quality Coors AD995 alumina shocked to roughly 5 and $7 \mathrm{GPa}$ (just below or at the HEL). The material is subsequently reshocked to just above its elastic limit. Results of these experiments do show some evidence of strength degradation in the elastic regime.

\section{INTRODUCTION}

There is an increasing body of evidence that certain brittle solids undergo strength loss during residence at a Hugoniot state below the Hugoniot elastic limit [HEL], especially for glass. Kanel et $\mathrm{al}^{1}$ observed a wave arrival corresponding to a reflection from a discrete propagating zone of strength loss in glass, a zone termed a failure wave. They also observed a relaxation in shear stress corresponding primarily to an increase in stress normal to the shock propagation direction. This is shown schematically in Fig. 1. Other evidence based on spall strength loss ${ }^{2}$ and photographic contrast ${ }^{3}$ has also been obtained supporting the theory that failure waves propagate in glass.

In alumina, spall strength loss for Hugoniots near (but still below) the HEL suggests that a similar process is occurring ${ }^{4}$. The body of evidence for such phenomena in alumina, however, is not nearly as extensive as for glass.

The objective of the present work is to assess the behavior of alumina initially shocked to below the HEL when reshocked to somewhat above the HEL.

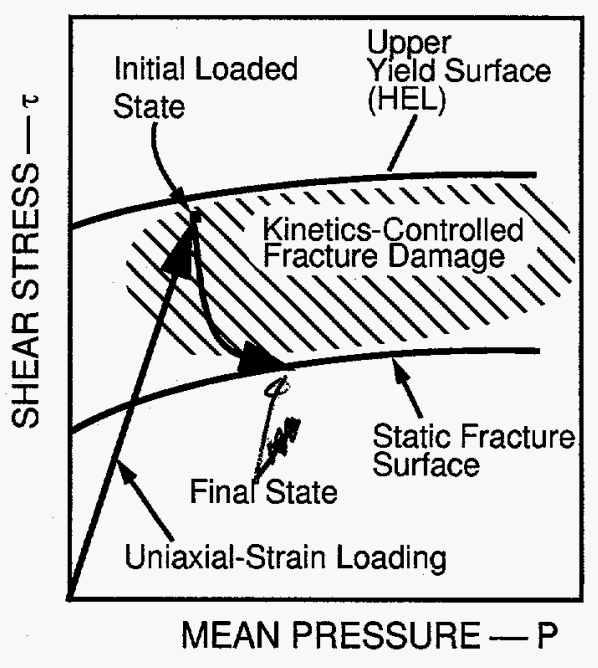

FIGURE 1. Process of sub-HEL material relaxation.

\section{TECHNIQUE}

Disks of Coors AD995 ceramic (initial density $\rho_{0}=3.89 \mathrm{gm} / \mathrm{cm}^{3}$ ) were tested in a transmittedwave geometry as shown in Fig. 2. This configuration provided an initial shock loading of the alumina chosen (via impact velocity) to slightly below the 


\section{DISCLAIMER}

This report was prepared as an account of work sponsored by an agency of the United States Government. Neither the United States Government nor any agency thereof, nor any of their employees, make any warranty, express or implied, or assumes any legal liability or responsibility for the accuracy, completeness, or usefulness of any information, apparatus, product, or process disclosed, or represents that its use would not infringe privately owned rights. Reference herein to any specific commercial product, process, or service by trade name, trademark, manufacturer, or otherwise does not necessarily constitute or imply its endorsement, recommendation, or favoring by the United States Government or any agency thereof. The views and opinions of authors expressed herein do not necessarily state or reflect those of the United States Government or any agency thereof. 


\section{DISCLAMMER}

Portions of this docament may be illegible in electronic image products. Images are produced from the best available original document. 


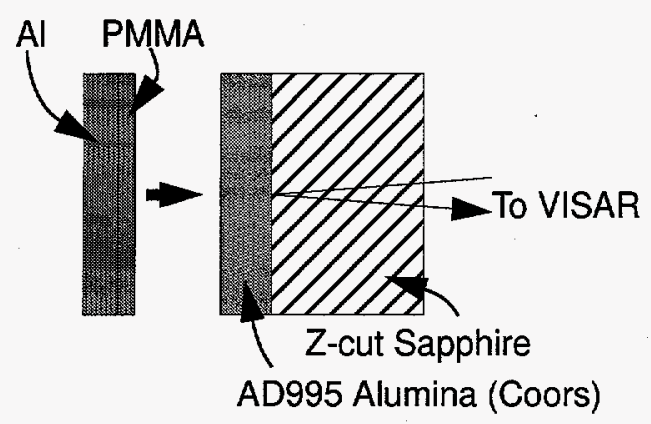

FIGURE 2. Configuration used for impact tests.

HEL, followed by a reloading above the HEL. A VISAR monitored the motion of the sample/sapphire interface, giving a nearly in situ measurement because of the close impedance match between the (unyielded) AD995 alumina and the window.

\section{RESULTS}

Observed velocity histories are given in Figure 3., together with critical experiment parameters. Axial stresses at yielding are shown.

The wave profiles have been analyzed through an explicit Lagrangian calculation comparing input and output wave profiles for the sample. Such an analysis includes corrections for sample/window shock impedance mismatch (small for the present samples).

It is interesting to compare the results of this analysis with results of an analogous analysis of Grady's ${ }^{5}$ waveforms, which were obtained by introducing a single shock, then release, into the alumina. Lithium fluoride windows were used for Grady's tests. Figure 4 shows an overall agreement between the two sets of results. Note that the diamond-anvil cell data show less compressibility than do the shock wave data for stresses above $10 \mathrm{GPa}$;

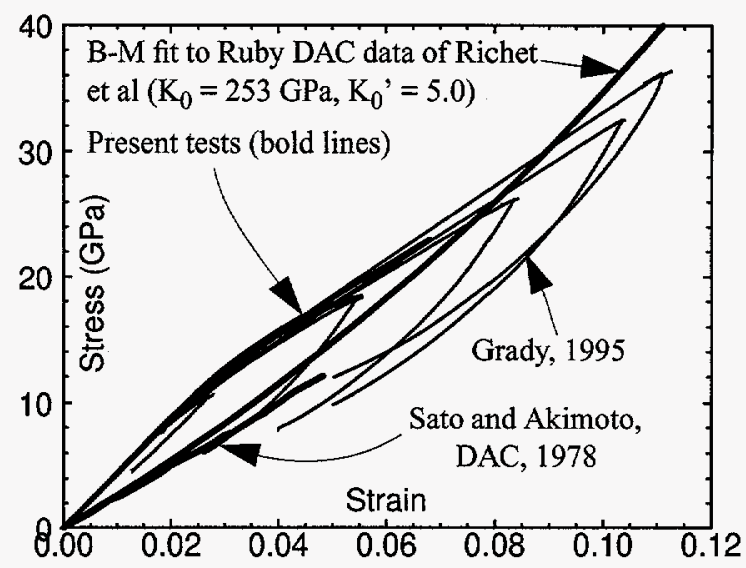

FIGURE 4. Stress-strain data for alumina, compared with diamond cell data ${ }^{6,7}$. Birch-Murnighan fits to the latter are shown.

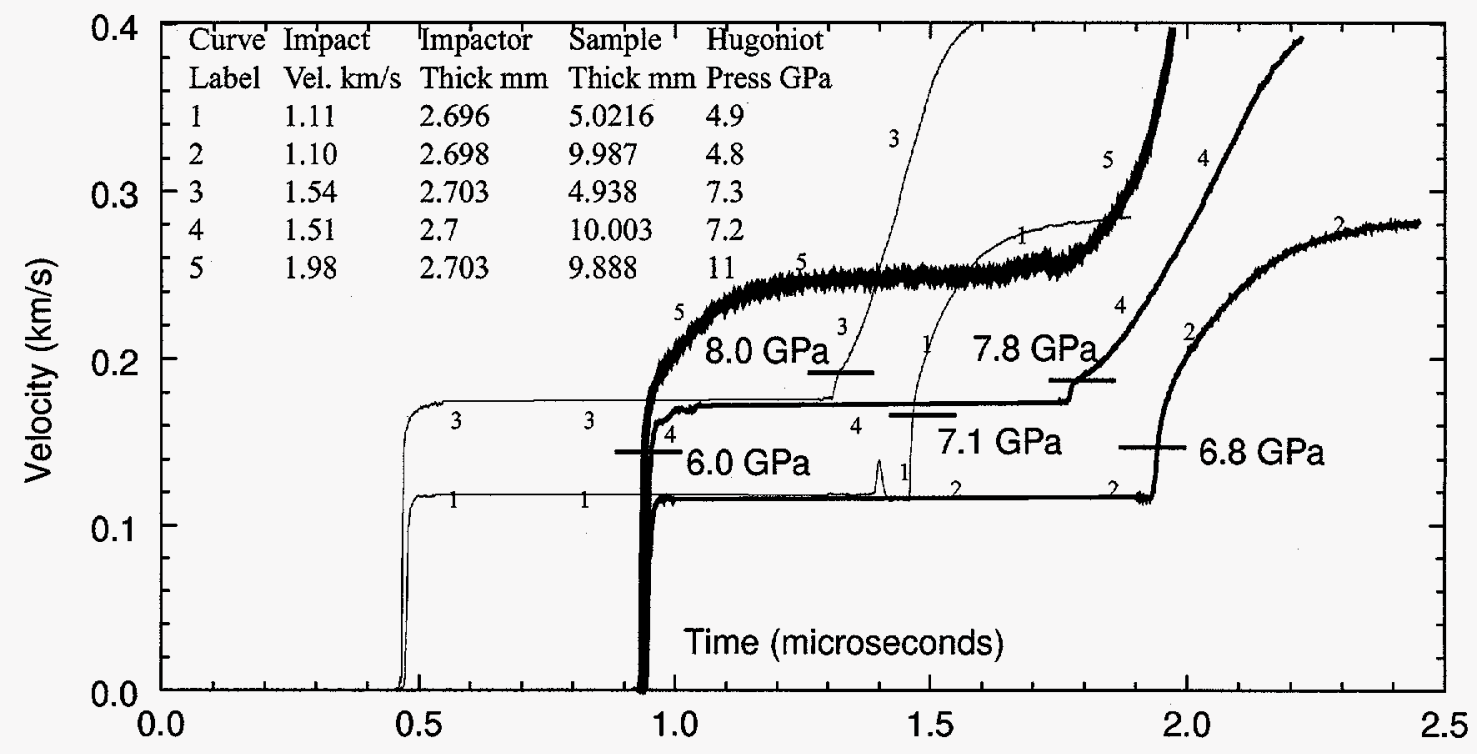

FIGURE 3. Wave profiles from present series of transmitted-wave experiments. Shot parameters as shown. 
these results do not permit the calculation of aboveHEL deviatoric stresses from deviations of the Hugoniot from the hydrostat. However, the yield strength of the material at the Hugoniot state may also be estimated as $3 / 4$ of the width of the stressstrain loop, or about $6 \mathrm{GPa}$.

The behavior of the alumina near the yield point may be seen better by converting the velocity profiles to stress-time profiles via the Lagrangian analysis described above. Results are shown in Fig. 5.
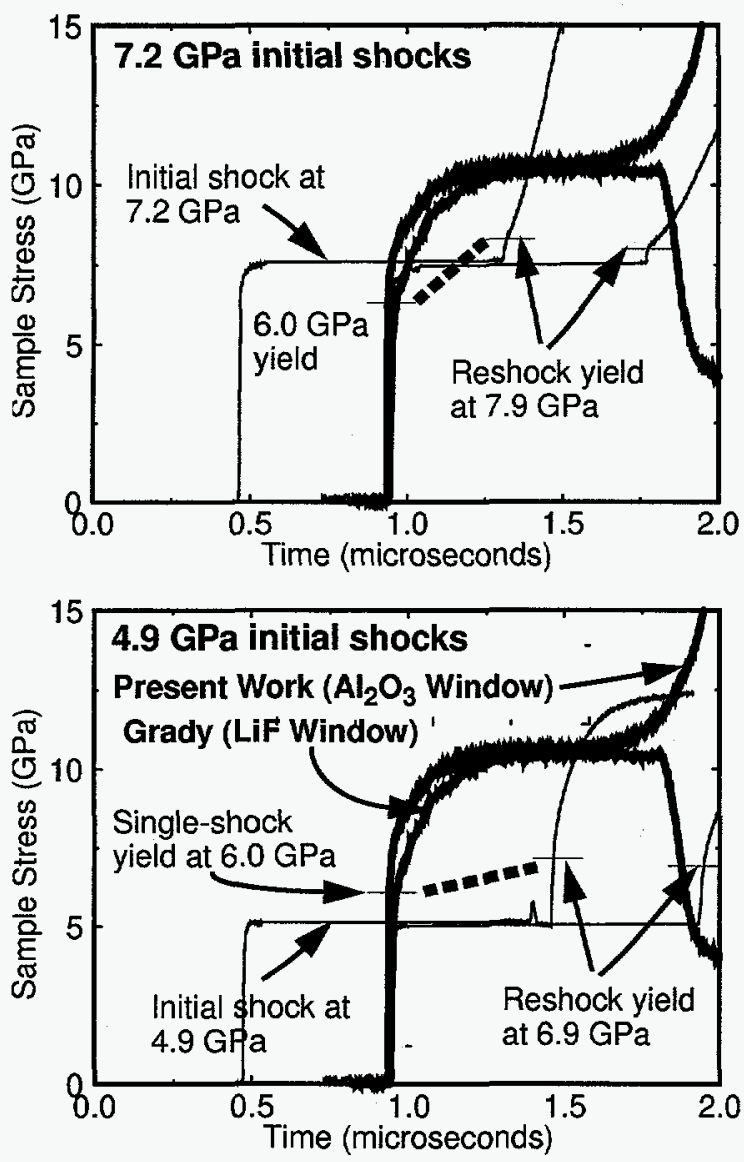

FIGURE 5. Comparison of present results (expressed as stress vs. time) with the lowest-stress single-shock result of Grady ${ }^{5}$. Bold lines represent single shocks to stresses above the HEL.

Note that the Fig. 5 curves represent in situ stresses rather than stresses which would actually be measured at the sample/window interface. This distinction is more important for the Grady results than for the present results. The window used does not appear to have a strong effect on the data plotted in this way.

Details of the HEL are better seen in a plot of wave speed vs. stress (Fig. 6). The HEL from the Grady single-shock data in fact range from $\sim 6 \mathrm{GPa}$ to $7.2 \mathrm{GPa}$. The data show two trends:

1. The yield stress appears to be higher for an initial shock closer to the HEL.

2. The yield stress appears to decrease with increased wave travel distance.

Both of these trends are consistent with a relaxation of shear stress during residence at the Hugoniot state. The evidence, however, is still relatively weak. Further tests to assess this hypothesis, underway, involve adjusting the thickness of the PMMA flyer plate to change the residence time of the material at the Hugoniot state prior to reloading.

\section{FURTHER INTERPRETATION}

In the Introduction the problem was stated in terms of shear stress relaxation. It is important to view the present results in those terms.

From the waveforms alone, it is only possible to calculate the axial stress. If elastic behavior persists, the Poisson's ratio $\left(0.23\right.$ to $\left.0.24^{5}\right)$ allows a cal-



FIGURE 6. Detail of HEL region of present data and Grady data, represented as stress vs. wave speed. Fine lines represen present data (circles show HEL values) and thick lines represen Grady single-shock data (squares show HEL values). 


\section{DRAFT}

culation of shear stress $\tau$ and mean pressure $\bar{\sigma}$ via:

$$
\begin{aligned}
& \tau=0.5 \sigma_{\text {axial }}(1-2 v) /(1-v) \\
& \bar{\sigma}=\sigma_{\text {axial }}-4 / 3 \tau
\end{aligned}
$$

The initial elastic, uniaxial strain loading is along a path given by (from Equations 1 and 2):

$$
\tau=\overline{3 \sigma} \mathrm{X} /(3-2 \mathrm{X}) \quad(\mathrm{X} \equiv(1-2 v) /(1-v))
$$

The reload points yield points lie on lines given by (from $\tau=1 / 2\left(\sigma_{\text {axial }}-\sigma_{\text {transverse }}\right)$ and $\bar{\sigma}=1 / 3$ $\left.\left(\sigma_{\text {axial }}+2 \sigma_{\text {transverse }}\right)\right)$ :

$$
\tau=3 / 4 \sigma_{\text {axial }}-3 / 4 \bar{\sigma}
$$

This, however, assumes that the material behavior remains elastic, i.e. that the Poisson's ratio still reflects material behavior.

Hence there is a continuum of points in $(\bar{\sigma}, \tau)$ space possibly corresponding to the reshock yield point, and other diagnostics will be required to completely define this material behavior.

\section{ACKNOWLEDGEMENTS}

This work performed at Sandia National Laboratories supported by the U. S. Department of Energy under contract DE-AC04-94AL85000. Sandia is a multiprogram laboratory operated by Sandia Corporation, a Lockheed Martin company, for the USDOE.

\section{REFERENCES}

3. Kanel, G. I., S. V. Rasorenov and V. E. Fortov, The failure waves and spallations in homogeneous brittle materials, pp. 451-454 in Shock Compression of Condensed Matter 1991, S. C. Schmidt, R. D. Dick, J. W. Forbes and D. G. Tasker (eds.), Elsevier, 1992.

4. Brar, N. S., S. J. Bless and Z. Rosenberg, Impact-induced failure waves in glass bars and plates, Appl. Phys. Lett., 59, 3396-3398, 1991.

5. Bourne, N. K., Z. Rosenberg and J. E. Field, High speed photography of compressive failure waves in glasses, $J$. Appl. Phys., 78, 3736-3739, 1995.

6. Rosenberg, $Z$. and Y. Yeshurun, Determination of the dynamic response of $\mathrm{AD}-85$ alumina with in-material manganin gauges, J. Appl. Phys., 58, 3077-3080, 1985.

7. Grady, D. E., Dynamic properties of ceramic materials, Sandia National Laboratories Report SAND94-3266, 1995.

8. Richet, P., J-A Xu and H-K Mao, Quasi-hydrostatic compression of ruby to $500 \mathrm{kbar}$, Phys. Chem. Minerals, 16, 207 $211,1988$.

9. Sato, Y. and S. Akimoto, Hydrostatic compression of four corundum-type compounds: $\alpha-\mathrm{Al}_{2} \mathrm{O}_{3}, \mathrm{~V}_{2} \mathrm{O}_{3}, \mathrm{Cr}_{2} \mathrm{O}_{3}$, and $\alpha$ $\mathrm{Fe}_{2} \mathrm{O}_{3}$,J. Appl. Phys., 50, 5285-5291, 1979.

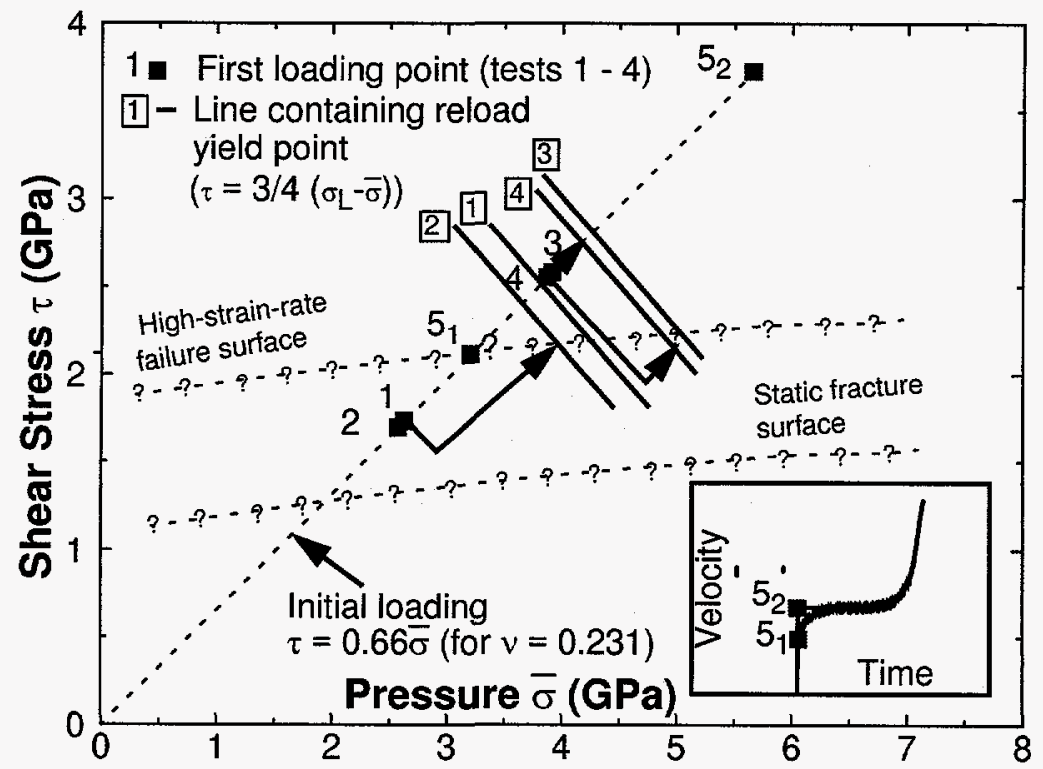

FIGURE 7. Interpretation of the present results in pressure vs. shear stress space. Initial loading is from $(0,0)$ to the loading points shown for the present experiments. Reloading is to some point along the heavy diagonal lines shown (present data cannot constrain where on this line) Inset shows how alternative values were chosen for the yield point on test 5 . 